\title{
AVALIAÇÃO DO POTENCIAL FITORREMEDIADOR DE CRAVINA-CHINESA CULTIVADA EM SOLO COM EXCESSO DE COBRE
}

\author{
Janine Farias Menegaes* \\ Alexandre Swarowsky ${ }^{*}$ \\ Rogério Antônio Belle***: \\ Fernanda Alice Antonello Londero Backes ${ }^{* * * *}$
}

RESUMO: A contaminação do solo por metais pesados, como $\mathrm{Cu}$ (cobre), é um problema agroambiental e socioeconômico, resultado da ação antrópica sobre o sistema solo-planta. $\mathrm{O} \mathrm{Cu}$ em excesso no solo afeta o desenvolvimento das plantas impactando no seu potencial produtivo. O presente estudo objetivou avaliar o potencial fitorremediador e o desenvolvimento da cravina-chinesa (Diantbus chinensis L.) cultivada em solo com excesso de $\mathrm{Cu}$, buscando uma agricultura de baixo impacto ambiental. O experimento foi realizado em casa de vegetação, em delineamento inteiramente casualizado. Após a análise de solo, o teor de Cu era de 188,7 mg kg-1, e adicionou-se quatro doses de $\mathrm{Cu}$ por quilo de solo: zero (sem adição), uma, duas e três vezes a quantidade de $\mathrm{Cu}$ presente no solo, com dez repetições. A adição das doses de $\mathrm{Cu}$ foi por meio de sulfato de cobre. Avaliou-se crescimento das plantas, macro e micronutrientes no tecido, fatores de translocação (FT), de bioacumulação da parte aérea (FCA) e de bioconcentração das raízes (FCO); taxa de extração de metal (MER); número efetivo de plantas totais $\left(\mathrm{PEN}_{\mathrm{T}}\right)$ e de parte aérea de plantas $\left(\mathrm{PEN}_{\mathrm{PA}}\right)$ para fitorremediar solos contaminados por $\mathrm{Cu}$. Observou-se que as doses de $\mathrm{Cu}$ não interferiram no desenvolvimento típico das plantas de cravina-chinesa e na disponibilidade nutricional para o crescimento e o desenvolvimento da cultura, mantendo suas características ornamentais. Assim, verificou-se que esta espécie apresenta potencial fitorremediativo para solo com excesso de $\mathrm{Cu}$, sendo eficiente na retenção do mesmo, sobretudo, nas raízes, indicando-a como planta de cobertura.

PALAVRAS-CHAVE: Áreas vitivinícolas; Dianthus chinensis L. Planta de cobertura.

\footnotetext{
"Engenheira Agrônoma e Dr. em Agronomia, Brasil. Autor correspondente: janine_rs@hotmail.com

*** Dr., PhD em Solos. Docente do Departamento de Engenharia Sanitária e Ambiental da Universidade Federal de Santa Maria (UFSM), Brasil.

**** Dr., Docente do Departamento de Fitotecnia da Universidade Federal de Santa Maria (UFSM), Brasil.

***** Dr., Docente do Departamento de Fitotecnia da Universidade Federal de Santa Maria (UFSM), Brasil.
} 


\section{EVALUATION OF THE PHY TOREMEDY POTENTIAL OF DIANTHUS CHINENSIS IN SOIL WITH EXCESSIVE COPPER}

ABSTRACT: Soil contamination by heavy metals, such as copper, is an agro-environmental and socio-economic issue, the result of anthropic activities on the soil-plant system. Excess $\mathrm{Cu}$ in the soil affects plant development and impacts their productivity. Current study evaluates the phytoremedy potential and development of Dianthus chinensis $\mathrm{L}$ cultivated in soil with excessive $\mathrm{Cu}$, for low environmental impact agriculture. The experiment was undertaken in a greenhouse, with a totally randomized design. After soil analysis, $\mathrm{Cu}$ rates were $188.7 \mathrm{mg} \mathrm{kg}^{-1}$, to which were added four $\mathrm{Cu}$ doses (copper sulfate) per kilo of soil: zero (without any addition), one, two, three times the quantity of $\mathrm{Cu}$ in the soil, with ten replications. Plant growth, macroand micro-nutrients in the tissues, translocation factors (FT), bioaccumulation of the aerial part (FCA), bioconcentration of roots (FCO), metal extraction rate (MER), effective number of total plants (PENT) and of the plants' aerial segment (PENPA) were evaluated for the phytoremedy of $\mathrm{Cu}$-contaminated soil. Doses of $\mathrm{Cu}$ did not interfere in the development of Dianthus chinensis L. plants and in the nutritional availability for growth and development of the culture, maintaining their ornamental characteristics. The species has a phytoremedy potential for soil with excess $\mathrm{Cu}$ and it is efficient in its retention, mainly in the roots, featuring a covering plant.

KEY WORDS: Vineyard areas; Dianthus chinensis L.; Covering plant.

\section{INTRODUÇÃO}

Ações antrópicas em busca do desenvolvimento econômico desencadearam a contaminação do sistema solo-água-atmosfera, especialmente em áreas agrícolas, resultado do uso demasiado de fertilizantes e de agrotóxicos, que favorecem a contaminação do solo, sobretudo, por metais pesados. Metais estes que apresentam características toxicológicas no ambiente, quando em excesso são altamente prejudiciais ao sistema solo-planta, influenciando na dinâmica das suas interações (OORTS, 2013). Alguns metais pesados, como cobre $(\mathrm{Cu})$, zinco $(\mathrm{Zn})$ e níquel (Ni) são considerados essenciais para crescimento e desenvolvimento das plantas, enquanto chumbo $(\mathrm{Pb})$ e cádmio $(\mathrm{Cd})$ são tóxicos, mesmo em níveis de elemento 
traço5 (GONÇALVES-JÚNIOR, 2013; JADIA; FULEKAR, 2009).

$\mathrm{O} \mathrm{Cu}$ em excesso atua, diretamente, sobre os mecanismos bioquímicos e fisiológicos das plantas em nível celular e molecular podendo resultar na desativação de enzimas e nos bloqueios dos grupos funcionais de moléculas metabolicamente importantes, reduzindo o funcionamento de organelas celulares e impedindo a fotossíntese (MACKIE; MÜLLER; KANDELER, 2012; SUMIAHADI; ACAR, 2018). Como micronutriente sua essenciabilidade varia de 5 a $20 \mathrm{mg} \mathrm{kg}^{-1}$, contudo, a absorção, a translocação e o acúmulo nos tecidos dependem, diretamente, da disponibilidade deste elemento no solo. E, quando em quantidades excessivas, provoca disfunções e distúrbios na planta que levam a fitotoxidez, assim inibindo seu crescimento e, consequentemente, perdas produtivas (KABATA-PENDIAS, 2011; MOOSAVI; SEGHATOLESLAMI, 2013).

Em geral, a descontaminação do solo é lenta, gradativa e onerosa. Apesar disso, há a técnica de fitorremediação que envolve o sistema solo-planta-contaminante e suas adaptações biogeoquímicas, sendo influenciada pelos processos fisiológicos das plantas, pelas características edafoclimáticas locais e pela distribuição espacial e concentração do contaminante, com a finalidade de degradar ou reduzir a níveis não tóxicos os mesmos no solo (JADIA; FULEKAR, 2009; MARIANO; OKURUMA, 2012).

A fitorremediação em solos contaminados com $\mathrm{Cu}$ tem demonstrado resultados eficientes e com baixo impacto ambiental utilizando espécies como Lolium multiflorum L. e Vicia sativa L. (OLIVEIRA et al., 2009), Cedrela fissilis Vell., Enterolobium contortisiliquum Morong. e Peltophorum dubium Taub. (CAIRES et al., 2011), Brassica spp., Avena sp., Silene vulgaris L, Elsholtzia splendens M. (MACKIE; MÜLLER; KANDELER, 2012), Bidens pilosa L. e Plantago lanceolata Lann. (ANDREAZZA et al., 2015), Sparganium erectum L. (PARZYCH, 2016), Achillea millefolium L., Artemisia vulgaris $\mathrm{L}$, , Papaver rhoeas $\mathrm{L}$, Tripleurospermum inodorum (L.) Sch. Bip. e Taraxacum officinale F. H. WIGG. (MIKOLAJCZAK; BOROWIAK; NIEDZIELSKI, 2017). Todavia, a seleção de plantas aptas para o cultivo nesses ambientes é uma prática necessária, uma vez que a interface solo-plantacontaminante caracteriza-se por um sistema aberto e complexo, sobretudo no que se refere à dinâmica nutricional e adaptação das espécies nos ambiente com estas características.

5 Elemento traço são elementos metálicos presentes em baixas concentrações (usualmente $<0,1$ dag $\mathrm{kg}^{-1}$ ) em solos e plantas (KABATA-PENDIAS, 2011). 
Neste contexto, as espécies da família Caryophyllaceae demonstraram papel importante para a adaptabilidade em solos pobres, ácidos e com altos teores de $\mathrm{Cu}$, por exemplo, os de áreas de mineração, empregando essas plantas em cobertura (SIMONA et al., 2012). Entre estas espécies, o Dianthus chinensis L. caracteriza-se pela alta produção de biomassa vegetal e exuberância de floração, sendo utilizada como planta de forração no paisagismo (LORENZI, 2013), e planta de cobertura em áreas contaminadas por metais pesados, como $\mathrm{Pb}, \mathrm{Zn}$ e $\mathrm{Cd}$, devido às suas habilidades fitorremediativas do solo (ZHUANG et al., 2007).

Assim, o presente estudo objetivou avaliar o potencial fitorremediador e o desenvolvimento da cravina-chinesa (Dianthus chinensis L.) cultivada em solo com excesso de $\mathrm{Cu}$, buscando uma agricultura de baixo impacto ambiental.

\section{MATERIAL E MÉTODOS}

O experimento foi conduzido em casa de vegetação na área experimental do Departamento de Fitotecnia da Universidade Federal de Santa Maria (2943'25" S; 5343’42" W e altitude de 95 m), em 2014. O clima na região é subtropical úmido (Cfa), segundo a classificação de Köppen-Geiger, com precipitação média anual acumulada de $1.769 \mathrm{~mm}$, temperatura média anual próxima de $19,2{ }^{\circ} \mathrm{C}$ e umidade do ar em torno de $78,4 \%$.

O solo utilizado foi coletado em área vitivinícola do município de Pinto Bandeira (RS), com 75 anos de cultivo, localizado na Serra Gaúcha, a profundidade 0-20 cm, classificado como Cambissolo Húmico. A Tabela 1 apresenta as seguintes características físico-químicas do solo, segundo o laudo da análise de solo antes do cultivo: 
Tabela 1. Característica físico-química do solo

\begin{tabular}{|c|c|c|c|c|c|c|c|c|c|}
\hline \multirow{2}{*}{\multicolumn{2}{|c|}{ Matéria orgânica (\%) }} & \multirow{2}{*}{ Argila (\%) } & \multirow{2}{*}{ Textura } & \multirow{2}{*}{\multicolumn{2}{|c|}{ pH água 1:1 }} & \multirow{2}{*}{ Índice SMP } & \multicolumn{3}{|c|}{ Saturação (\%) } \\
\hline & & & & & & & $\mathrm{Al}$ & & \\
\hline \multicolumn{2}{|c|}{5} & 12 & 4 & & 5,8 & 6,2 & 0,0 & \multicolumn{2}{|c|}{80,8} \\
\hline $\mathrm{Ca}$ & $\mathrm{Mg}$ & CTC $_{\text {efet. }}$ & $\mathrm{CTC}_{\mathrm{pH} 7}$ & $S$ & P-Mehlich & K & $\mathrm{Cu}$ & $\mathrm{Zn}$ & $\mathrm{B}$ \\
\hline \multicolumn{4}{|c|}{ cmolc $\mathrm{dm}^{-3}$} & \multicolumn{6}{|c|}{ $\mathrm{mg} \mathrm{dm}^{3}$} \\
\hline 11,4 & 2,8 & 15 & 18,5 & 15,7 & 66,1 & 264 & 188,7 & 250,8 & 0,8 \\
\hline
\end{tabular}

O delineamento experimental foi inteiramente casualizado, com tratamentos compostos por quatro doses de $\mathrm{Cu}$ adicionadas por quilo de solo: i) dose 1 - sem adição, permanecendo a quantidade de $\mathrm{Cu}$ existente no solo (188,7 $\mathrm{mg} \mathrm{kg}{ }^{-1}$ ) diagnosticado por análise química supracitada; ii) dose 2 - adição de uma vez a quantidade de $\mathrm{Cu}$ existente no solo $\left(377,4 \mathrm{mg} \mathrm{kg}^{-1}\right)$; iii) dose 3 - adição de duas vezes a quantidade de $\mathrm{Cu}$ existente no solo $\left(566,1 \mathrm{mg} \mathrm{kg}^{-1}\right)$; e iv) dose 4 adição de três vezes a quantidade de $\mathrm{Cu}$ existente no solo $\left(754,8 \mathrm{mg} \mathrm{kg}^{-1}\right)$, com dez repetições. A adição das doses de $\mathrm{Cu}$ foi por meio de sulfato de cobre pentahidratado $\left[\mathrm{CuSO}_{4} .5 \mathrm{H}_{2} \mathrm{O}\right]$.

A semeadura da cravina-chinesa (Dianthus chinensis L.), variedade Carmine Rose, ocorreu em bandejas de poliestireno expandido (isopor) com duas sementes por alvéolo, em substrato comercial H-Decker ${ }^{\circledR}$, com irrigações diárias. Após 15 dias, transplantaram-se as mudas nos vasos de número 15 (1,3 L de volume, 14,5 cm de diâmetro superior, $11 \mathrm{~cm}$ de diâmetro inferior, $12 \mathrm{~cm}$ de altura, de material plástico na cor preto), com distribuição aleatória sobre as bancadas no interior da casa de vegetação no espaçamento de 10 vasos $\mathrm{m}^{-2}$, com irrigações a cada dois dias.

Ao final do ciclo de cultivo avaliou-se a altura da planta determinada desde o nível do solo no recipiente até o último botão floral, com trena graduada, selecionando as plantas centrais, na mesma ocasião foi mensurado o número de hastes florais e flores por vaso. A fitomassa fresca da parte aérea e radicular por planta foi determinada pelo método de pesagem, após a colheita as amostras foram secas em estufa de ventilação forçada a $65^{\circ} \mathrm{C}$ até atingir massa constante, utilizouse a balança digital de precisão $0,001 \mathrm{~g}$. Na sequência as subamostras do material vegetal seco foram trituradas em moinho tipo Willey, submetidas à digestão nítricoperclórica e a quantificação das concentrações dos elementos $\mathrm{Cu}$ (cobre), P (fósforo), 
K (potássio), Ca (cálcio), Mg (magnésio), Fe (ferro), Mn (manganês), Zn (zinco), B (boro), Mo (molibdênio) e Co (cobalto) nos tecidos vegetais foram efetuadas por espectrofotometria de absorção atômica. Os teores de $\mathrm{Cu}$ no solo após o cultivo foram amostrados por análise físico-química.

O fator de translocação (FT), o fator de bioacumulação da parte aérea (FCA) e o fator de bioconcentração das raízes (FCO) foram avaliados conforme as metodologias descritas por Caille, Zhao e Mcgrath (2005) e Yoon et al. (2006), a taxa de extração de metal (MER) ocorreu conforme a fórmula descrita por Mertens, Luyssaert e Verheyen (2005) e os cálculos do número efetivo de plantas totais $\left(\mathrm{PEN}_{\mathrm{T}}\right.$ ) e do número efetivo de parte aérea de plantas $\left(\mathrm{PEN}_{\mathrm{PA}}\right)$ para avaliar a capacidade de fitorremediar solos contaminados por metais pesados foram elaborados conforme descrito e adaptado por Sun, Zhou e Diao (2008), expressas nas Equações:

$$
\begin{aligned}
& \mathrm{FT}=\mathrm{Cu}_{\mathrm{PA}} / \mathrm{Cu}_{\mathrm{R}} \\
& \mathrm{FCA}=\mathrm{Cu}_{\mathrm{PA}} / \mathrm{Cu}_{\mathrm{S}} \\
& \mathrm{FCO}=\mathrm{Cu}_{\mathrm{R}} / \mathrm{Cu}_{\mathrm{S}} \\
& \mathrm{MER}=\left(\left(\mathrm{Cu}_{\mathrm{T}} \times \mathrm{FM}_{\mathrm{T}}\right) /\left(\mathrm{Cu}_{\mathrm{S}} \times \mathrm{M}_{\mathrm{R}}\right)\right) \times 100 \\
& \mathrm{PEN}_{\mathrm{T}}=\left(\mathrm{FM}_{\mathrm{T}} \times \mathrm{Cu}_{\mathrm{T}}\right) / \mathrm{FM}_{\mathrm{T}} \\
& \mathrm{PEN}_{\mathrm{PA}}=\left(\mathrm{FM}_{\mathrm{PA}} \times \mathrm{Cu}_{\mathrm{PA}}\right) / \mathrm{FM}_{\mathrm{PA}}
\end{aligned}
$$

em que:

$\mathrm{Cu}_{\mathrm{PA}}=$ concentração de $\mathrm{Cu}$ na fitomassa seca da parte aérea;

$\mathrm{Cu}_{\mathrm{R}}=$ concentração de $\mathrm{Cu}$ na fitomassa seca radicular;

$\mathrm{Cu}_{\mathrm{T}}=$ concentração de $\mathrm{Cu}$ na fitomassa seca total;

$\mathrm{Cu}_{\mathrm{s}}=$ teor de $\mathrm{Cu}$ disponível no solo após o cultivo;

$\mathrm{FM}_{\mathrm{T}}=$ fitomassa seca total;

$\mathrm{FM}_{\mathrm{PA}}=$ fitomassa seca da parte aérea; 
$\mathrm{FM}_{\mathrm{R}}=$ fitomassa seca radicular;

$M_{R}=$ massa do volume de solo enraizada pela espécie.

Os dados foram submetidos à análise de variância (ANOVA) e regressão, a 5\% de probabilidade de erro, auxiliado pelo software estatístico SISVAR (FERREIRA, 2011).

\section{RESULTADOS E DISCUSSÃO}

O cultivo das plantas de cravina-chinesa em solo com excesso de $\mathrm{Cu}$, em diferentes doses, foi satisfatório em todos os tratamentos com crescimento e desenvolvimento típico da espécie, sobretudo na altura de planta, emissão de hastes florais e número de flores e radicular (Figura 1 e Gráfico 1).

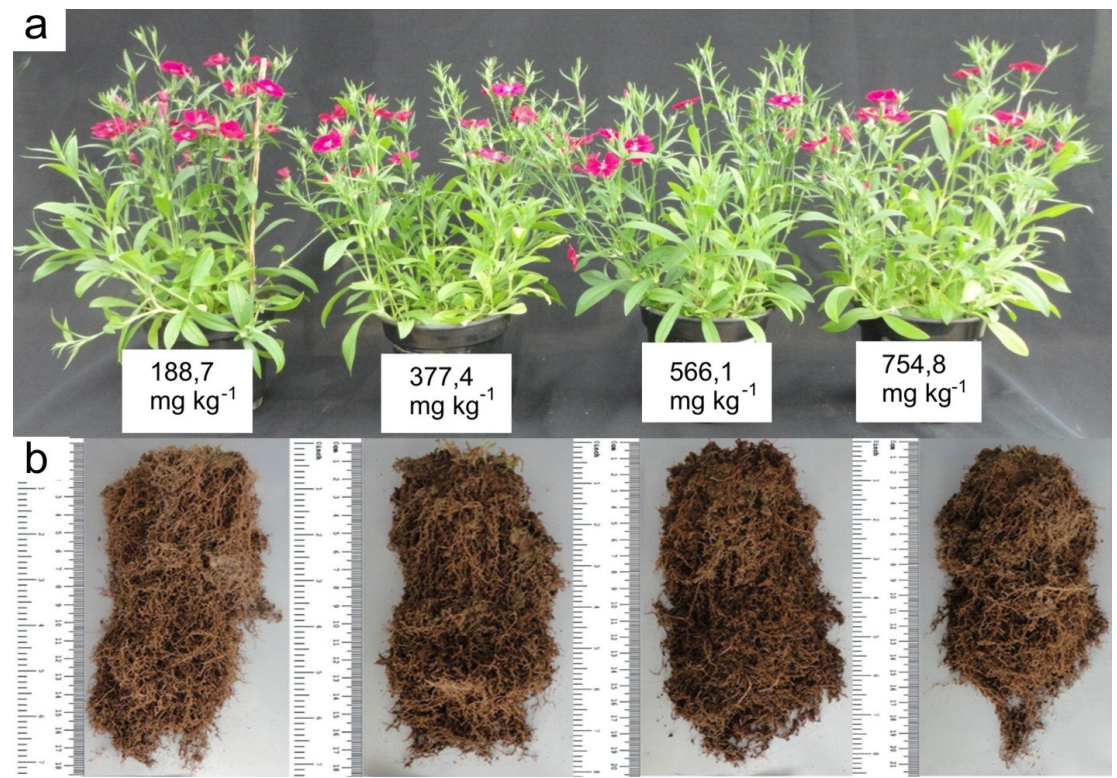

Figura 1. Cravina-chinesa (Dianthus chinensis L.) em floração (a) e sistema radicular (b) cultivada em diferentes doses de $\mathrm{Cu}$ adicionadas no solo. 

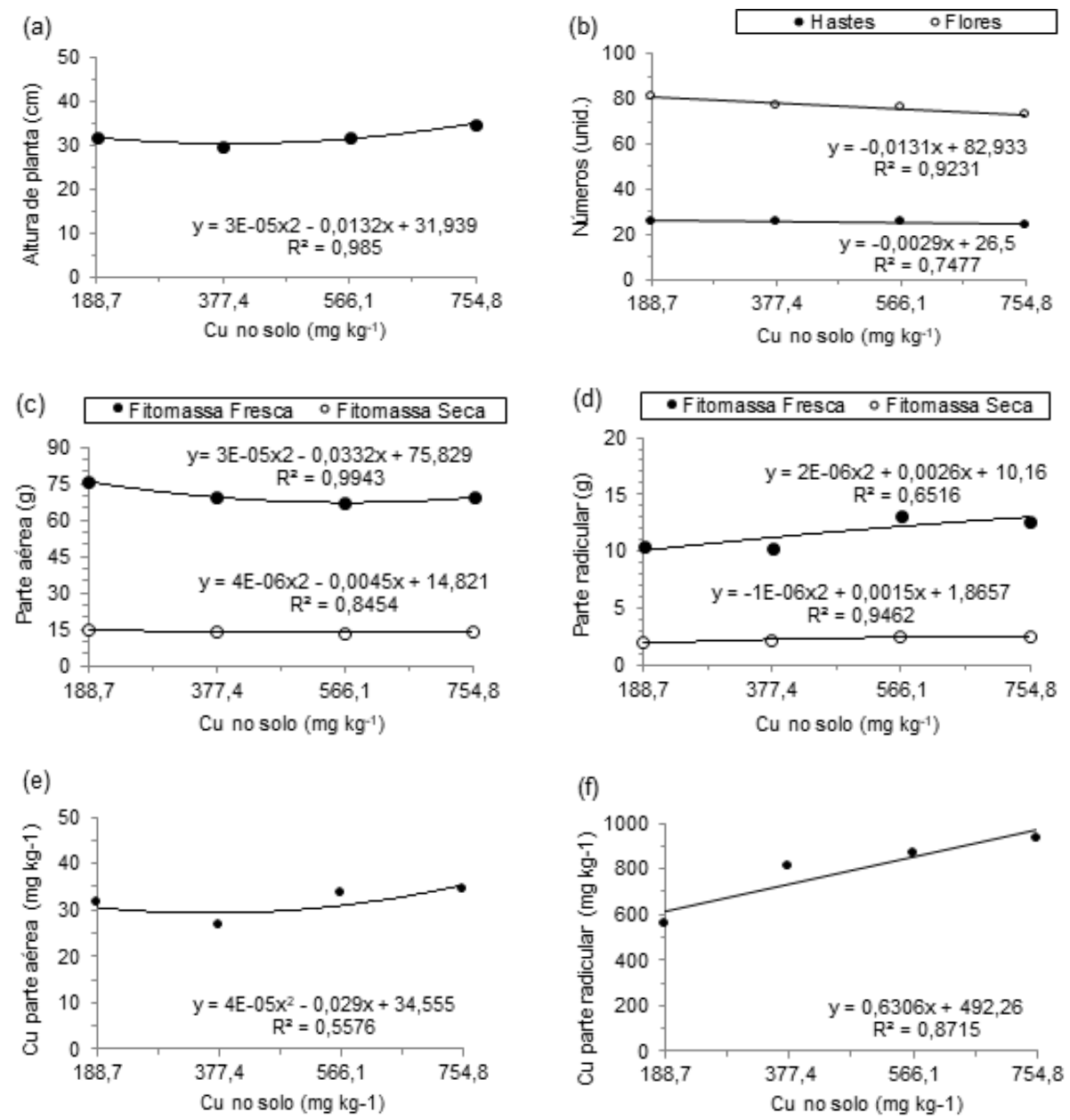

Gráfico 1. Altura da planta (a), número de flores e hastes (b), fitomassa fresca e seca da parte aérea (c), fitomassa fresca e seca da parte radicular (d), conteúdo de $\mathrm{Cu}\left(\mathrm{mg} \mathrm{kg}^{-1}\right)$ na fitomassa das partes aérea (e) e radicular (e) da cravina-chinesa (Diantbus chinensis L.) após 180 dias de cultivo nas diferentes doses de $\mathrm{Cu}$ adicionadas no solo.

Estes resultados indicam que a cravina-chinesa torna-se tolerante ao cultivo em áreas com alta quantidade de $\mathrm{Cu}$ no solo. De acordo com os trabalhos de Simona et al. (2012) e Zhuang et al. (2007), este desempenho é devido à adaptabilidade da espécie às diferentes condições nutricionais do solo, sobretudo por metais pesados.

Corroborando com os nossos resultados, Andreazza et al. (2015) cultivando Bidens pilosa L. e Plantago lanceolata Lann. em solo com excesso de $\mathrm{Cu}$ não 
observaram danos fitotóxicos nas plantas estudadas. Em contrapartida, Menegaes et al. (2017a; 2017b) verificaram que as espécies de Zantedeschia spp. e Dendranthema grandiflora Tzevelev cv. Dark Fiji, respectivamente, apresentaram tolerância ao cultivo em solos com alto teor de $\mathrm{Cu}$, contudo ambas as espécies apresentaram sintomas de fitotoxidez, afetando negativamente a floração.

O cultivo da cravina-chinesa foi em $\mathrm{pH} \mathrm{5,8,} \mathrm{na} \mathrm{faixa} \mathrm{de} \mathrm{alta} \mathrm{disponibilidade}$ de $\mathrm{Cu}$ no solo e, consequentemente, resultando na grande concentração deste elemento nas raízes (Gráfico 1f). Oorts (2013) relata que aproximadamente 33\% do $\mathrm{Cu}$ disponível é absorvido pela planta em solo com pH 6 e 100\% em pH 4.

A essenciabilidade de $\mathrm{Cu}$, em média para as plantas, varia de 5 a $20 \mathrm{mg}$ $\mathrm{kg}^{-1}$ (PRADO, 2008; KABATA-PENDIAS, 2011). Observou-se neste experimento que o conteúdo deste elemento em fitomassa seca foi acima do valor supracitado, sem danos ou perdas produtivas no cultivo da espécie, bem como das suas características ornamentais.

Verificou-se que a partição do conteúdo de Cu na fitomassa seca da cravinachinesa, em média, foi de 3,8 e 96,2\% para a parte aérea e, nas raízes, respectivamente, com a proporcionalidade de 1:25. Yoon et al. (2006) relatam que o $\mathrm{Cu}$ tende a acumular nas raízes devido à sua baixa capacidade de translocação.

Marsola, Miyazawa e Pavan (2005), cultivando Phaseolus vulgaris L. em solos contaminados por metais pesados, entre eles o $\mathrm{Cu}$, atribuíram que a grande diferença entre as concentrações deste elemento na parte aérea e na raiz deve-se ao mecanismo de redução da difusão de cátion no interior do tecido, protegendo-o da intoxicação. Zancheta et al. (2011) relatam que a alta retenção de Cu nas raízes é um indicativo de tolerância da planta ao cultivo em solos com excesso deste elemento. Menegaes et al. (2017a) verificaram em estudos com a espécie de Zantedeschia spp., cultivada em solo com alto teor de $\mathrm{Cu}$, o acúmulo deste elemento nos tubérculos com baixa translocação para a parte aérea, afetando negativamente o seu desenvolvimento e floração.

A capacidade de absorção do metal pela planta e a produção de biomassa são os fatores preponderantes para a eficiência da sua extração (MCGRATH; ZHAO, 2003). No solo, os metais pesados, como o $\mathrm{Cu}$, tendem a acumularem-se nas camadas superiores, as agricultáveis, em função da sua baixa mobilidade, no entanto, em condições ácidas há maior mobilidade e adsorção pelos óxidos favorece 
a disponibilidade do $\mathrm{Cu}$, tornando-o fitodisponível (SUMIAHADI; ACAR, 2018; OLIVEIRA et al., 2009).

A produção de biomassa vegetal e o desenvolvimento radicular são requisitos básicos para a avaliação de planta ser considerada fitorremediadora do solo (MCGRATH; ZHAO, 2003; MERTENS; LUYSSAERT; VERHEYEN, 2005). Deste modo, observou-se nas Figuras 1 e Gráfico 1 que a biomassa vegetal e o florescimento da cravina-chinesa foram exuberantes com bom desenvolvimento radicular. Todavia, este pleno desenvolvimento também depende das adaptações biogeoquímicas da planta ao sistema solo-planta-contaminante (JADIA; FULEKAR, 2009; MIKOLAJCZAK; BOROWIAK; NIEDZIELSKI, 2017), sendo avaliada pela nutrição mineral da planta em matéria seca.

O Gráfico 2 apresenta os conteúdos dos nutrientes na fitomassa seca da parte aérea e radicular das plantas de cravina-chinesa após o cultivo de 180 dias em diferentes doses de $\mathrm{Cu}$ adicionadas no solo. Verificou-se que os conteúdos médios dos nutrientes $\mathrm{P}, \mathrm{K}, \mathrm{Ca}$ e $\mathrm{Mg}$ em fitomassa seca na parte aérea foram nas quantidades de 2,$4 ; 25,1 ; 11,5 ;$ e $3,7 \mathrm{~g} \mathrm{~kg}^{-1}$, respectivamente, e em fitomassa seca radicular nas quantidades de 1,$6 ; 10,7 ; 7,5 ; \mathrm{e} 3,4 \mathrm{~g} \mathrm{~kg}^{-1}$, respectivamente.

Valores estes estão acima daqueles considerados ideais por Malavolta (1997) para espécies do gênero Dianthus, em que o autor estipulou teores foliares entre 2,5 a 8,0 mg kg para P e Mg; 28 a $60 \mathrm{mg} \mathrm{kg}^{-1}$ para K e 10 a $20 \mathrm{mg} \mathrm{kg}^{-1}$ para Ca.

Em geral, verificou-se um aumento do conteúdo dos nutrientes $\mathrm{Fe}, \mathrm{Mn}$, $\mathrm{Zn}$, Mo e Co em fitomassa seca radicular conforme o incremento de $\mathrm{Cu}$ no solo, exceto para o B que obteve desempenho oposto aos demais nutrientes, nas mesmas condições (Gráfico 2). Em fitomassa seca da parte aérea os mesmos nutrientes foram pouco variáveis para todas as doses de $\mathrm{Cu}$ no solo.

Os conteúdos médios de Fe na fitomassa das partes aérea e radicular foram de 0,2 e $8,6 \mathrm{~g} \mathrm{~kg}^{-1}$, respectivamente. Valores superiores aos relatados por Kirkby e Römheld (2007) como essenciais as plantas (50 a $100 \mathrm{mg} \mathrm{kg}^{-1}$ ). Contudo, não foram observados sintomas de fitotoxicidade por Fe nas plantas cultivadas. O conteúdo médio de Mn na fitomassa da parte aérea e nas raízes foi zero e 47,8 $\mathrm{mg} \mathrm{kg}^{-1}$, respectivamente. A deficiência de Mn na parte aérea pode ocasionar clorose internerval foliar (PRADO, 2008), o que não foi observado nestas condições experimentais. 
- Parte radicular - Parte aérea

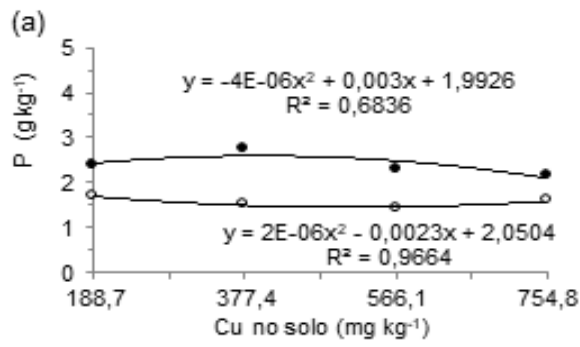

(c)

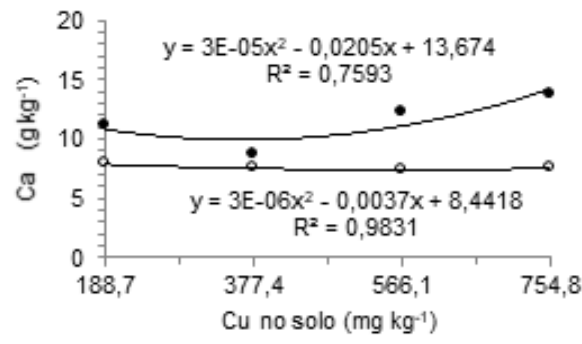

(e)

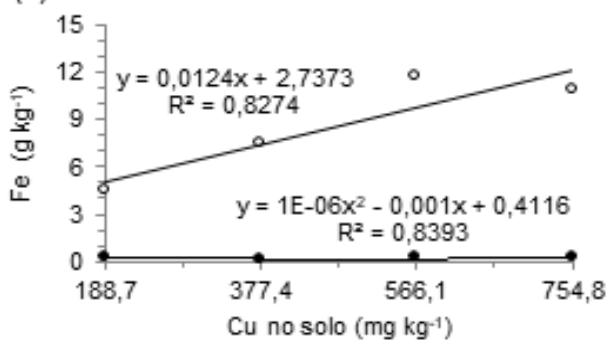

(g)

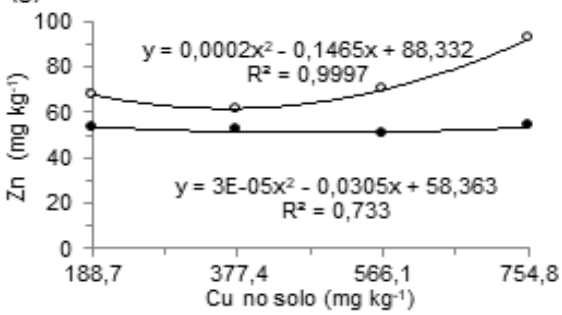

(b)

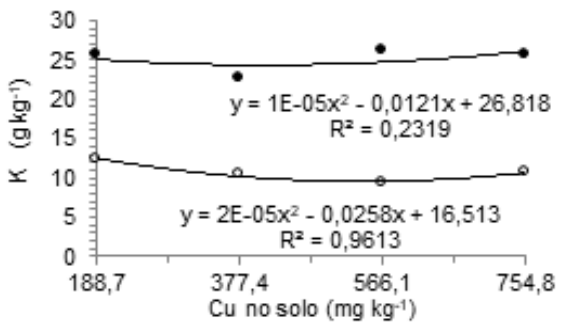

(d)

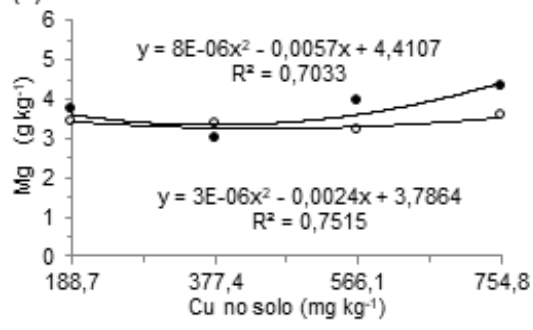

(f)

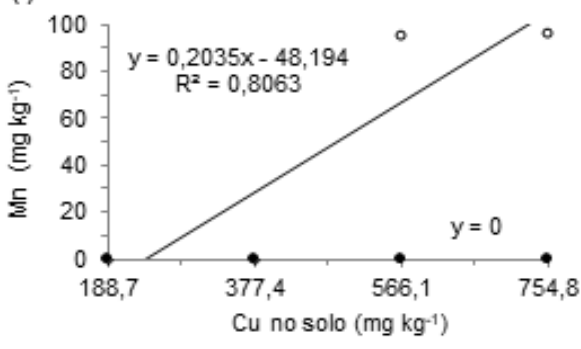

(h)

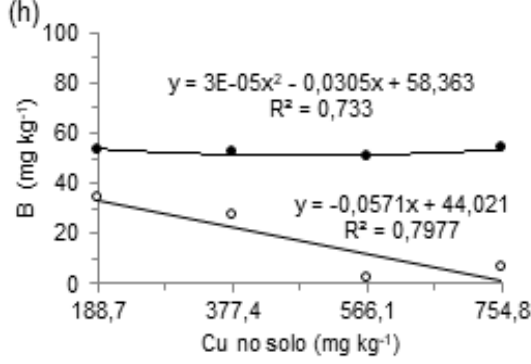



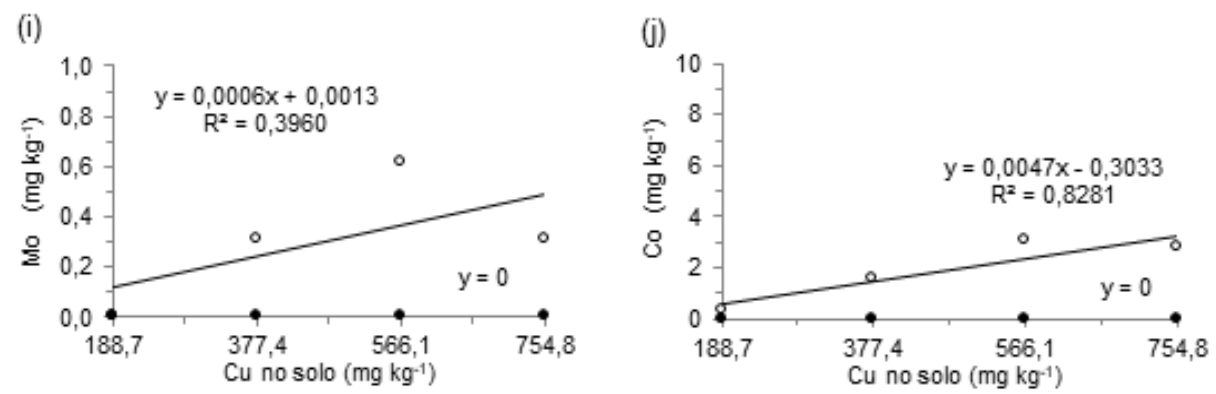

Gráfico 2. Conteúdo dos nutrientes P (fósforo; a), K (potássio; b), Ca (cálcio; c), Mg (magnésio; d), Fe (ferro; e), Mn (manganês; f), Zn (zinco; g), B (boro; h), Mo (molibdênio; i) e Co (cobalto; j) na fitomassa seca da parte aérea e radicular das plantas de cravina-chinesa (Diantbus chinensis L.) após 180 dias de cultivo nas diferentes doses de $\mathrm{Cu}$ adicionadas no solo.

Verificou-se que o conteúdo médio de Zn na fitomassa seca, na parte aérea e nas raízes, foi de 50,3 e 73,0 $\mathrm{mg} \mathrm{kg}^{-1}$, respectivamente. Em geral, a exigência nutricional de $\mathrm{Zn}$ pelas plantas varia de 10 a $30 \mathrm{mg} \mathrm{kg}^{-1}$ (KIRKBY; RÖMHELD, 2007). Zhuang et al. (2007), selecionando materiais vegetais com habilidades fitorremediativas em áreas contaminadas por $\mathrm{Pb}, \mathrm{Zn}$ e $\mathrm{Cd}$, verificaram que a cravinachinesa apresentou altas concentrações na parte aérea de $146 \mathrm{mg} \mathrm{kg}^{-1} \mathrm{~Pb} ; 282 \mathrm{mg}$ $\mathrm{kg}^{-1} \mathrm{Zn}$; e $6 \mathrm{mg} \mathrm{kg}^{-1} \mathrm{Cd}$, e, nas raízes, de $163 \mathrm{mg} \mathrm{kg}^{-1} \mathrm{~Pb}$; $228 \mathrm{mg} \mathrm{kg}^{-1} \mathrm{Zn}$; e 7,2 mg $\mathrm{kg}^{-1} \mathrm{Cd}$, tornando-o tolerante a ambientes contaminados por estes elementos, sem prejuízo morfofisiológico, indicando esta espécie como planta fitorremediadora para ambientes com excesso destes metais pesados.

O conteúdo médio de B (boro) na fitomassa seca da cravina-chinesa, nas partes aérea e radicular, foram de 52,5 e $17,1 \mathrm{mg} \mathrm{kg}^{-1}$, respectivamente. $\mathrm{O}$ boro apesar da sua baixa mobilidade torna-se disponível e é absorvido pela planta com pH próximo de 6,0 (PRADO, 2008), o que pode explicar o acúmulo de B na fitomassa seca da cravina-chinesa. Mo e Co foram os micronutrientes com menor expressão acumulativa na fitomassa seca da cravina-chinesa, sobretudo na parte aérea, com zero para o Mo e Co. As exigências nutricionais em teor foliar destes nutrientes (Mo e Co) são relativamente baixas quando comparados com os demais micronutrientes que variam de 0,03 a 3,5 $\mathrm{mg} \mathrm{kg}^{-1}$ (PRADO, 2008). Entretanto, são igualmente essenciais para o pleno crescimento e desenvolvimento vegetal. Os maiores acúmulos de Mo e Co foram em fitomassa seca radicular de 0,3 e $1,9 \mathrm{mg} \mathrm{kg}^{-1}$, respectivamente. 
O Gráfico 3 expõe os fatores de fitorremediação do solo, e destaca-se o fator de bioconcentração do elemento na raiz (FCO), o qual exibe a relação entre o residual de $\mathrm{Cu}$ no solo e a concentração deste elemento nas raízes em fitomassa seca, o que caracteriza a espécie de cravina-chinesa como planta acumuladora de $\mathrm{Cu}$. Zhuang et al. (2007) verificaram habilidades fitorremediativas da cravina-chinesa em áreas contaminadas por metais pesados, como $\mathrm{Pb}, \mathrm{Zn}$ e $\mathrm{Cd}$, apresentando FCO de 0,$18 ; 0,34 ;$ e 1,3 , respectivamente. Deste modo, a cravina-chinesa pode ser considerada uma planta tolerante a ambientes contaminados por metais pesados, com capacidade fitoextrativa, concentrando metais, principalmente nas raízes, sem prejuízo ao seu desenvolvimento característico.

A capacidade de fitoextração é mensurada através de fatores de acumulação, transferência e/ou concentração, que quanto mais próximo de um (1), maior a eficiência absorvente ou retentora do metal em tecidos vegetais (MCGRATH; ZHAO, 2003). Contudo, observou-se que a translação de $\mathrm{Cu}$ na planta foi baixo, expressado pelo fator de translocação (FT). Resultados semelhantes foram encontrados por Andreazza et al. (2015) para as espécies Bidens pilosa L. e Plantago lanceolata Lann. cultivadas em solos de vitivinicultura com excesso de $\mathrm{Cu}$, com FT nos valores de 0,04 e 0,15 , respectivamente. Menegaes et al. (2017b), avaliando o potencial fitorremediativo de Dendranthema grandiflora Tzevelev cv. Dark Fiji para solo com excesso de $\mathrm{Cu}$, observaram valores médios de 0,27 ; 0,65; e 2,42 para FT, FCA e FCO, respectivamente, com alta concentração deste elemento nas raízes. Devido à sua baixa mobilidade, o Cu não está prontamente disponível à planta, permanecendo fortemente ligado às paredes celulares das raízes.

Observa-se que o número efetivo de plantas de cravina-chinesa capazes de remover do solo $1 \mathrm{~g} \mathrm{de} \mathrm{Cu}$, na sua totalidade (PENt) e na parte aérea (PENpa), varia conforme as doses adicionadas no solo e, por conseqüência, implicou na variação da taxa de extração de $\mathrm{Cu}$ (MER). Esta taxa, MER, indica em porcentagem a aptidão da planta em extrair o metal do solo em função da sua produção de fitomassa (MERTENS; LUYSSAERT; VERHEYEN, 2005).

Verificou-se uma grande diferença entre os números efetivos de plantas totais (PENt) e de parte aérea (PENpa), isto atribui-se ao elevado acúmulo de $\mathrm{Cu}$ nas raízes. Zancheta et al. (2011) verificaram semelhante desempenho de acúmulo 
de $\mathrm{Cu}$ nas raízes das plantas de Canavalia ensiformis (L.) DC Bean cultivadas em solução nutritiva com excesso de $\mathrm{Cu}$, os autores atribuíram este desempenho à tolerância das plantas ao metal.

A mobilidade de $\mathrm{Cu}$ nos tecidos vegetais pode aumentar com o nível de acúmulo do elemento, principalmente nas raízes (KABATA-PENDIAS, 2011), afetando a translocação e, consequentemente, o fator de bioacumulação na parte aérea (FCA). Entretanto, resultados deste experimento demonstraram que os fatores FCA mantiveram-se constantes para todas as doses adicionadas de $\mathrm{Cu}$ no solo, corroborando a tolerância da cravina-chinesa cultivada em áreas com excesso deste elemento.

Em áreas de cultivo de videiras, plantas de cobertura tendem a auxiliar no controle da erosão e na fertilidade do solo (MACKIE; MÜLLER; KANDELER, 2012), preferencialmente as nativas e as ornamentais que se desenvolvem vigorosamente em ambientes contaminados por metais pesados, sendo a fitorremediação uma estratégia de boa relação custo-benefício, especialmente ambiental (MARQUES; AGUIAR; SILVA, 2011; OLIVEIRA et al., 2009), possibilitando, assim, uma agricultura de baixo impacto ambiental, ao mesmo tempo em que o embeleza.

(a)

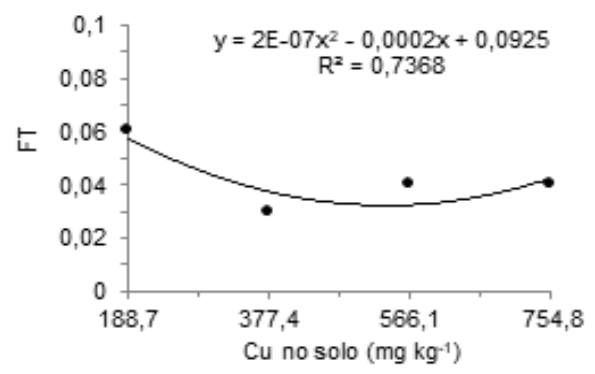

(c)

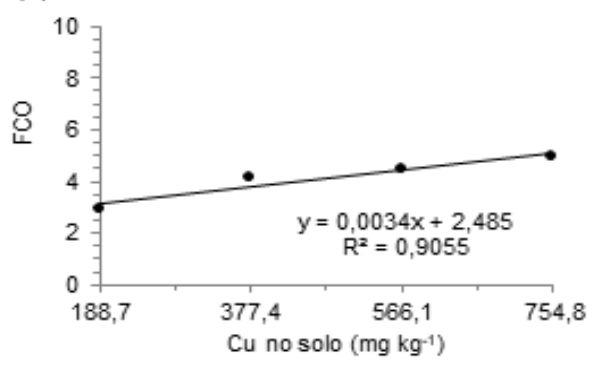

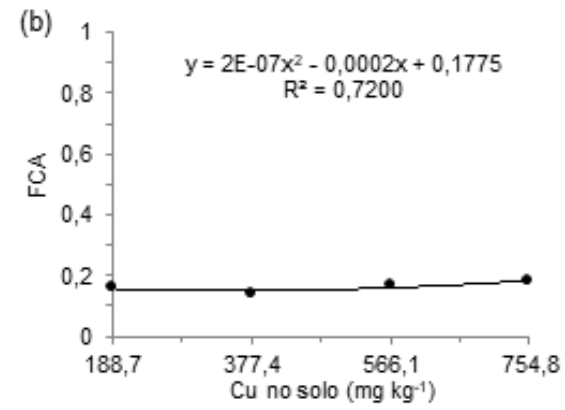

(d)

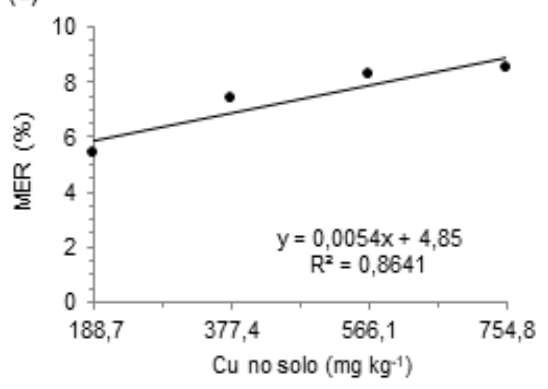


(e)

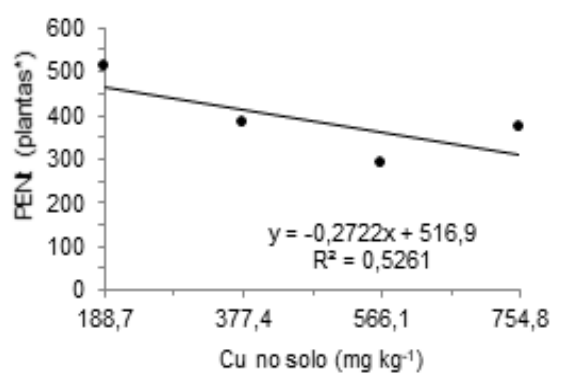

(f)

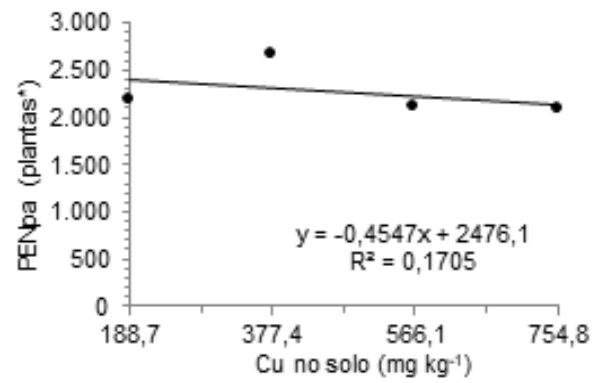

Gráfico 3. Fator médio de translocação (FT; a), fator médio de bioacumulação na parte aérea (FCA; b), fator médio de bioconcentração na raiz (FCO; c), taxa de extração de cobre (MER; d), número efetivo de plantas totais (PENt; e) e número efetivo de parte aérea de plantas (PENpa; f) no cultivo de Dianthus chinensis L. em função das doses de $\mathrm{Cu}$ adicionadas no solo. *Número de plantas para remover $1 \mathrm{~g}$ de $\mathrm{Cu}$ em 180 dias de cultivo.

\section{CONCLUSÃO}

A cravina-chinesa (Dianthus chinensis L.) obteve desenvolvimento de biomassa vegetal com floração característica e radicular nas diferentes doses de $\mathrm{Cu}$ (cobre) adicionadas no solo, sem prejuízo à disponibilidade nutricional, mantendo seus atributos ornamentais e apresentando eficiência na retenção de $\mathrm{Cu}$, sobretudo nas raízes. A tolerância de cultivo desta espécie em solo com excesso de $\mathrm{Cu}$ indica-a como planta com potencial fitorremediador, utilizando-a como planta de cobertura, propiciando uma agricultura de baixo impacto ambiental.

\section{REFERÊNCIAS}

ANDREAZZA, R.; BORTOLON, L.; PIENIZ, S.; BENTO, F. M.; CAMARGO, F. A. O. Evaluation of two Brazilian indigenous plants for phytostabilization and phytoremediation of copper-contaminated soils. Brazilian Journal of Biology, v. 75, n. 1, p. 868-877, 2015. DOI: 10.1590/1519-6984.01914. 
CAILLE, N.; ZHAO, F. J.; MCGRATH, S. P. Comparison of root absorption, translocation and tolerance of arsenic in the hyperaccumulator Pteris vittata and the non hyperaccumulartor Pteris tremula. New Phytologist, v. 165, p. 755-761, 2005. DOI: 10.1111/j.1469-8137.2004.01239.x.

CAIRES, S. M.; FONTES, M. P. F.; FERNANDES, R. B. A.; NEVES, J. C. L.; FONTES, R. L. F. Desenvolvimento de mudas de cedro-rosa em solo contaminado com cobre: tolerância e potencial para fins de fitoestabilização do solo. Revista Árvore, v. 35, n. 6, p. 1181-1188, 2011. DOI: 10.1590/S0100-67622011000700004.

FERREIRA, D. F. Sisvar: a computer statistical analysis system. Ciência e Agrotecnologia, v. 35, p. 1039-1042. 2011. DOI: 10.1590/S1413-70542011000600001.

GONÇALVES-JÚNIOR, A. C.; CARVALHO, E. A.; COELHO, G. F.; SCHWANTES, D.; NACKE, H.; MORAES, A. J. Disponibilidade de nutrientes e elementos potencialmente tóxicos para as plantas de hissopo em solo arenoso sob adubação mineral e orgânica. Scientia Agraria Paranaensis, v. 12, n. 2, p. 105-114, 2013. DOI: 10.1818/sap.v12i2.6451.

JADIA, C. D.; FULEKAR, M. H. Phytoremediation of heavy metals: recent techniques. African Journal of Biotechnology, v. 8, n. 6, p. 921-928, 2009. DOI: https://doi.org/10.5897/AJB2009.000-9152.

KABATA-PENDIAS, A. Trace elements in soils and plants. Boca Raton: CRC Press/ Taylor \& Francis Group, 2011. 548 p.

KIRKBY, E. A.; RÖMHELD, V. Micronutrients in plant physiology: functions, uptake and mobility. York: The International Fertiliser Society, 2007. 24 p.

LORENZI, H. Plantas para jardim no Brasil - herbáceas, arbustivas e trepadeiras. Nova Odessa: Instituto Plantarum, 2013. 1120 p.

MACKIE, K. A.; MÜLLER, T.; KANDELER, E. Remediation of copper in vineyards e A mini review. Journals Environmental Pollution, n. 167, p. 16-26, 2012. DOI: 10.1016/j.envpol.2012.03.023.

MALAVOLTA, E. (ed.) Avaliação do estado nutricional das plantas: princípios e aplicações. Piracicaba: POTAFOS, 1997. 319 p.

MARIANO, D. C.; OKUMURA, R. S. Aspectos agronômicos, uso pelo homem e mecanismos da fitorremediação: uma revisão. Revista em Agronegócio e Meio Am- 
biente, Maringá, v. 5, n. ed. esp., p. 85-101, 2012.

MARQUES, M.; AGUIAR, C. R. C.; SILVA, J. J. L. S. Desafios, técnicas e barreiras sociais, econômicas e regulatórias na fitorremediação de solos contaminados. Revista Brasileira de Ciência do Solo, v. 35, n. 1, p. 1-11, 2011. DOI: 10.1590/S010006832011000100001.

MARSOLA, T.; MIYAZAWA, M.; PAVAN, M. A. Acumulação de cobre e zinco em tecidos do feijoeiro em relação com o extraído do solo. Revista Brasileira de Engenharia Agrícola e Ambiental, v. 9, n. 1, p. 92-98, 2005. DOI: 10.1590/S141543662005000100014 .

MCGRATH, S. P.; ZHAO, F. J. Phytoextraction of metals and metalloids from contaminated soils. Current Opinion in Biotechnology, v. 14, n. 3, p. 277-282, 2003.

MENEGAES, J. F.; BACKES, F. A. A. L.; BELLÉ, R. A.; SWAROWSKY, A.; SALAZAR, R. S. S. Avaliação do potencial fitorremediador de crisântemo em solo com excesso de cobre. Horticulture Ornamental, v. 23, n. 1, p. 63-71. 2017a. DOI: 10.14295/ oh.v23i1.915.

MENEGAES, J. F.; SWAROWSKY, A.; BACKES, F. A. A. L.; BELLÉ, R. A.; IZÁRIO FILHO, H. J. Consumo hídrico de calla lily submetida ao manejo de irrigação via solo e teores de cobre. Irriga, Botucatu, v. 22, n. 1, p. 74-86, 2017b. DOI: 10.15809/ irriga.2017v22n1p74-86.

MERTENS, J.; LUYSSAERT, S.; VERHEYEN, K. Use and abuse of trace metal concentrations in plants tissue for biomonitoring and phytoextraction. Environmental Pollution, v. 138, n. 1, p. 1-4, 2005. DOI: 10.1016/j. envpol.2005.01.002.

MIKOLAJCZAK, P.; BOROWIAK, K.; NIEDZIELSKI, P. Phytoextraction of rare earth elements in herbaceous plant species growing close to roads. Environmental Science and Pollution Research International, v. 24, n. 16, p. 14091-14103, 2017. DOI: $10.1007 /$ s11356-017-8944-2.

MOOSAVI, S. G.; SEGHATOLESLAMI, M. J. Phytoremediation: a review. Advance in Agriculture and Biology, v. 1, n. 1, p. 5-11, 2013. DOI: 10.15192/PSCP.AAB.

OLIVEIRA, D. L.; ROCHA, C.; MOREIRA, P. C.; LAUDARES, S. O. Plantas nativas do cerrado: uma alternativa para fitorremediação. Revista Estudos, Goiânia, v. 36, n. 11-12, p. 1141-1159, 2009. DOI: 10.18224/est.v36i6.670. 
OORTS, K. Copper. In: ALLOWAY, B. J. (ed.) Heavy metals in soils - trace metals and metalloids in soils and their bioavailability. $3^{\text {th }}$ ed. Springer Environmental Pollution, v. 22, p. 367-394, 2013.

PARZYCH, A. E. Accumulation of chemical elements by organs of Sparganium erectum L. and their potential use in phytoremediation process. Journal of Ecological Engineering, v. 17, n. 1, p. 89-100, 2016. DOI: 10.12911/22998993/61195.

PRADO, R. M. Nutrição de plantas. São Paulo: UNESP, 2008. 408 p.

SIMONA, L.; CERASELA, P.; LAZAR, A.; MARIA, B. Influence of growth regulators on morphogenetic processes under in vitro condition. Journal of Horticulture, Forestry and Biotechnology, v. 16, n. 2, p. 197-202, 2012.

SUMIAHADI, A.; ACAR, R. A review of phytoremediation technology: heavy metals uptake by plants. IOP Conference Series: Earth and Environmental Science, v. 142, n. 1, p. 1-9, 2018. DOI: 10.1088/1755-1315/142/1/012023.

SUN, Y.; ZHOU, Q.; DIAO, C. Effects of cadmium and arsenic on growth and metal accumulation of $\mathrm{Cd}$ hyperaccumulator Solanum nigrum L. Bioresource Technolology, v. 99, n. 1, p. 1103-1110, 2008. DOI: 10.1016/j.biortech.2007.02.035.

YOON, J.; CAO, X.; ZHOU, Q.; MA, L. Q. Accumulation of Pb, $\mathrm{Cu}$, and $\mathrm{Zn}$ in native plants growing on a contaminated Florida site. Science of the Total Environment, v. 368, p. 456-464, 2006. DOI: 10.1016/j.scitotenv.2006.01.016.

ZANCHETA, A. C. F.; ABREU, C. A.; ZAMBROSI, F. C. B.; ERISMANN, N. M.; LAGÔA, A. M. M. A. Fitoextração de cobre por espécies de plantas em solução nutritiva.

Bragantia, v. 70, n. 1, p. 737-744, 2011. DOI: 10.1590/S0006-87052011000400002.

ZHUANG, P.; YANG, Q. W.; WANG, H. B.; SHU, W. S. Phytoextraction of heavy metals by eight plant species in the field. Water Air Soil Pollut, v. 184, p. 135-242, 2007. DOI: $10.1007 / \mathrm{s} 11270-007-9412-2$.

Recebido em: 25/01/2018

Aceito em: 26/09/2018 